\title{
Secondary caries and microleakage
}

\section{Asbjørn Jokstad*}

${ }^{*}$ Corresponding address:

Department of Clinical Dentistry, Faculty of Health Sciences, UiT, The Arctic University of Norway, Hansine Hansens v 86, N-9019 Tromsø, Norway. Tel.: (+47) 77649153

E-mail address: asbjorn.jokstad@uit.no 


\title{
Abstract
}

Objectives: To critically appraise experimental ex vivo research that has focussed on secondary caries, and to offer possible explanations for the seemingly poor correlation to clinical observations.

Methods: The literature relating to the etiopathogenesis or prevention of secondary caries gained from experimental ex vivo research was reviewed, with particular emphasis on microleakage and artificial caries-like lesions.

\begin{abstract}
Results: It is doubtful whether a caries wall lesion can exist independently of an outer enamel caries lesion. Microleakage experiments apparently continue to emerge regardless of multiple reviews questioning the reliability and validity of the method. Several of the approaches used to generate artificial caries-like lesions are very aggressive. Remarkably little discussion has evolved about how these aggressive approaches create microenvironments that do not occur in reality. Corrosion- and biodegradation products may influence the biofilm qualitatively and quantitatively and it is difficult to replicate these variables in any ex vivo environment. Clinical data sampling method, patient demography as well as study methodology influences the incidence and prevalence estimates of secondary caries. Clinical results based on clinical work in settings where cost per unit time is of nominal concern do not provide any indications on how the restorative material will perform when placed by the average dentists in the mouths of their spectrum of patients during a busy workday.

Recommendations: The term "wall lesion" including its variants is ill defined, has been, and is still being used indiscriminately. Stakeholders should avoid using this ambiguous label due to its connotation to an entity that does not exist per se.
\end{abstract}

Keywords

Biofilms; Corrosion; Dental Caries; Dental Materials 


\section{Introduction}

Secondary caries is the most commonly reported reason for re-restoration of teeth, regardless of restorative material. This conclusion has been consistent in multiple narrative and systematic reviews on the clinical performance of dental restorations published over the last few decades [1-3].

For obvious ethical reasons, it is not feasible to conduct clinical trials to monitor the progress of initial secondary caries adjacent to restoration margins, with the objective of studying etiopathogenesis and/or to identifying potential prognostic factors. Prognostic factors are likely associated with the patient, the operator and restorative material, including the structure of the tooth-restoration interface following optimal, as well as suboptimal handling and placement of the restorative material $[2,3]$.

Consequently, stakeholders with a strategy to decrease rates of secondary caries by improving restorative materials or material handling procedures are forced to statistically correlate as best as possible one, two or combinations of specific properties of existing restorative materials or handling procedures with reported rates of secondary caries in different clinical studies with various methodological qualities. Such statistics can be deceptive, because of a range of likely biases and possible confounding of both the independent and dependent variables in the majority of existing clinical studies.

Planning, conducting and reporting relevant outcomes of clinical comparative trials is logistically challenging, costly and potentially unpredictable if the study participant attrition is so high that adequate study power cannot be maintained. Moreover, correctly handled restorative materials placed under optimal conditions remain intact for an extensive time. Manufacturers may question a prioritizing of limited research funds to conduct clinical studies to evaluate the degrees of flawlessness of restorations monitored for anything less than 3 years. Moreover, to the author's knowledge, there is no evidence that a satisfactory clinical performance after 1 or 2 years is predictive of good long-term performance. It is therefore debatable whether the results of any clinical study of less than 3 years should have any impact at all on consideration of change of existing material compositions or material handling procedures other than to reject materials exhibiting an unacceptably high early failure rate. 
Stakeholders have therefore pursued alternative strategies to improve our understanding of how to develop innovative restorative materials which reduce the risk of secondary caries formation. Both academia and industry have designed numerous ingenious laboratory models and protocols for in situ experimental studies with the hoped objective of minimizing adhesion of cariogenic biofilms, preventing the occurrence of secondary caries adjacent to restorations, and elucidating the reasons for the deterioration of the restorative materials including the tooth-restoration interface.

Unfortunately, the correlation between microleakage around restorations or artificial caries-like lesions adjacent to restorations generated in vitro or in situ is poor versus tooth-restoration interface qualities measured in vitro or in vivo. It is also poor versus reported incidences of secondary caries observed in clinical efficacy or effectiveness studies [4-10]. There are probably multiple reasons for the incongruence between experimental data and clinical observations of secondary caries. The objective of this review is to critically appraise the existing experimental research with a focus on etiopathogenesis or prevention of secondary caries, and to explore possible explanations for the seemingly poor correlation to clinical observations.

\section{Dental caries}

A full review of the continuum of dental caries is outside of the scope of this article, but some features of this disease warrants a brief review in the context to the secondary caries puzzle.

Caries develops first in the enamel, a tissue with densely packed uniaxial crystallites with inter- and intraprismatic micropores that are 1-30 $\mathrm{nm}$ wide. The tissue structure display a type of molecular sieve behaviour and is anisotropic to light [11, 12]. The anisotropy is due to both its intrinsic (or crystalline) birefringence, as well as a form (or textural) birefringence (also known as structure anisotropy). When the enamel demineralizes, the intrinsic birefringence changes, but the form birefringence persists because pores between the enamel prisms remain oriented and they have a diameter and separation that is much smaller than the wavelength of visible light (390 to 700 nanometers). 
Transilluminated ground sections of enamel with caries demonstrates in most situations four distinct zones within the caries lesion when viewed in an optical microscope. The zones represent different optical properties of the tissue and are particularly discernible when the ground section is imbibed in a medium with a refractive index similar to intact enamel in a polarized light microscope (PLM). Investigators have used either water (R.I.=1.33), alcohols (R.I.=1.33-1.43), Thoulet's solution, consisting of potassium mercuric chloride $($ R.I. $=1.41-1.62)$ or quinoline $(R . I .=1.62)$ to enhance the separation of the enamel lesion zones in the microscope as well as estimating pore sizes as a function of molecular size of the imbibition media. A narrow superficial zone appears intact, probably because of precipitation of mineral ions interfacing the pellicle, saliva and biofilms in vivo, alternatively some fluid in vitro. Immediately below the surface zone is the body zone, which is more extensive and contains microporosity levels between 25\% and 50\% [13]. Two zones deeper have less microporosities and are characterized by smaller diameters. The first visible carious change contains few micropores, while the succeeding stage contains more, but smaller micropores and these are too minute for quinoline to infiltrate because of its molecular size. Hence, the two zones appear in the PLM as respectively, translucent and dark and hence their designation [14, 15]. While the enamel caries lesion progress, the dentin immediately below the lesion hypermineralizes [16], often labelled as sclerotization of the dentinal tubuli [17]. On all surfaces, with some exceptions occlusally once the caries lesion advances to the point that dentin starts to demineralize the periphery of the caries lesion in the dentin corresponds to that of the periphery of the enamel lesion [18]. It is only under rapid and extensive caries development with cavitation and heavily infected dentin that dentinal caries can progress along the dentin-enamel junction to undermine the enamel [16].

Several approaches for creating artificial caries-like lesions have been developed, some specifically tailored to create lesions in enamel or in dentin or in root cement [19-22]. Both human and non-human, mainly bovine, teeth or tooth specimens are used. Two techniques to create artificial caries-like lesions dominates. The most common is the use of an acidified substance or solution without [20], or with buffering [21], and with or without $\mathrm{pH}$-cycling [22]. A second approach is an exposure to an acidified broth containing usually some strain of Strepotococcus mutans. The ultimate hope is to build 
the artificial mouth, or at least a steady state microcosm, to study caries processes. In spite of a range of dental plaque biofilm models systems [23], or mathematical models [24] as well as elaborate contraptions [25], we have not succeeded yet to simulate the complexities of the intraoral ecology and microenvironment.

An alternative approach to create artificial caries-like lesions is the use of in situ models [26], where specimens from human or non-human teeth are mounted in a dental device and worn by the study subjects for various periods. The surface of the specimens are often covered or machined to increase dental plaque retention [27]. In situ models are versatile, and therefore used for multiple research objectives, such as assessing erosive or cariogenic potential of various substances. The inverse is also possible, by appraising the potential for remineralization following application of various oral care products, foremost the ones containing fluoride, on preconditioned specimens. When the objective is to create artificial caries-like lesions, it is not uncommon that the study participants are instructed to "speed up" the process by repeatedly bathing the specimens, e.g. in a $20 \%$ sucrose solution four times per each day.

Mineral loss in dental tissues can be expressed as differences in the three parameters lesion depth $\left(L_{d}\right)$, mineral loss value $(\Delta Z)$ or mineral lost per unit lesion length $(R)$. A lesion is often defined by a mineral content that is $5 \%$ lower than the sound enamel and depth is defined as the distance from the outer surface. Mineral loss value is the integrated surface area between the mineral distribution tracings of the carious and sound tissue while the mineral lost per unit lesion length is the ratio between the two, i.e., $\Delta Z / L_{d}[28]$.

It is well known that the different approaches to create artificial caries-like lesions in vitro and in situ produce different mineral loss profiles of the surface and subsurface zones in the enamel [29, 30], as well as in the dentin [31] as well as root cement [32]. These differences can be quite large, e.g., a carboxymethyl cellulose gel (6\%) at $\mathrm{pH}=5$ causes approximately 33 volume \% mineral loss in enamel per day, while an unstirred demineralization solution at $\mathrm{pH}=5$ causes 13 and $26 \%$ volume $\%$ mineral loss in enamel per hour, with and without fluorides added respectively. The demineralization rate increase by 1.6 when the solution was used on dentin surfaces [33]. 
Several strategies have been adopted to create artificial caries-like lesions adjacent to restorations, often without consideration of the very aggressive nature of the methodology with likely negative effects on the restorative material and of course not occurring in reality intra-orally. An additional confounder is that the restorative materials in many papers have been exposed to the aggressive environment immediately after the clinical setting time, which is not necessarily synonymous with a fully hardened or polymerized material. Hence, the adoption of methodologies for causing artificial carieslike lesions in enamel have perhaps been too uncritically extrapolated to create artificial caries-like lesions adjacent to restorations without full consideration of all potential confounders [34]. A particularly interesting phenomenon is that artificial caries-like lesions in dentin will subsequently hyper-remineralize upon exposure to a solution containing fluorides [35]. The phenomenon has been the basis for testing multiple fluoride-containing restorative materials with a measurable effect in the laboratory, but with disappointing results clinically. Moreover, real-life dentinal caries is not limited only to demineralization, but becomes heavily infected by mono- or multispecies biofilms, which is difficult to reproduce fully in vitro. The circumstance may perhaps not be significant when the research focus is to elucidate the chemistry of demineralizationremineralization of artificial caries-like lesions in the enamel. However, the situation is different when the research focus is to appraise the demineralization-remineralization of artificial caries-like lesions adjacent to restorations made from materials with alleged anticariogenic properties, as presented and discussed in a subsequent section.

Techniques to estimate the mineral contents of natural caries lesions or artificial carieslike lesions in teeth and tooth specimens can be categorized as destructive and nondestructive. The former encompasses chemical analyses, microhardness testing, optical birefringence, confocal light microscopy or laser scanning microscopy (CLSM) with or without fluorescence markers, transverse microradiography (TMR) and microprobe analyses. Non-destructive methods include surface microhardness testing, iodine absorptiometry, longitudinal microradiography (LMR), light scattering and iodide penetration. Each detection method carries benefits and disadvantages with regard to discrimination threshold in dental tissues, resolution, time, costs and complexity [36]. More recent innovations such as energy-dispersive spectroscopy (SEM-EDX), Raman 
spectroscopy, and Fourier-transform infrared spectroscopy (FTIR) allow detection of minuscule changes or differences of mineralization levels. In clinical settings, some of the later methods have been supplemented with light-, infrared- or laser-induced fluorescence, electrical conductivity and computerized radiography with or without algorithms for automated detection of lesions. The most recent promising tools for potential use in clinical settings to detect demineralization of teeth are based on optical coherence tomography (OCT) [37], and particularly polarization-sensitive optical coherence tomography (PS-OCT) in combination with near-infrared light [38].

\section{Restorative materials and the tooth-restoration interface}

The range of restorative materials today has never before been so extensive and the inherent tooth-restoration interfaces differ accordingly (Figure 1). Descriptors of the interface for all types of restorative materials are "margin", "adaptation or adaptability" or "gap". Other terms are primarily associated with particular restorative material. E.g., the term "seal or sealing" is used mostly in relation to adhesive materials, while "ditch" or "crevice" is restricted to amalgams and "fit" or "discrepancy" are applied predominantly to indirect restorations regardless of the material composition. The different terminology hints at the fact that the chemistry and mechanical properties of the tooth-restoration interfaces are vastly different as a function of the restorative material.

Moreover, the tooth-restoration interfaces are never static, but in a complex dynamic equilibrium with substances and minerals in the saliva and in the more or less porous hard tissues of the tooth. This is manifested clinically as corrosion products around amalgam restorations and cement washout around indirect restorations, likely influenced by the width of the luting cement space. For restorations made from glassionomer cement restorations and resin composites, including the hybrids ranging from resin-modified glass-ionomers to polyacrylate-modified resin composites, there are no particular manifestation of the state of the tooth-restoration interface except for marginal staining, which is often related to a patient life-style factor. For most polymers, we know today that particular fatigue processes lead to degradation of polymers, including in the tooth-restoration interfaces [39-41]. Fatigue degradation processes can only be studied by experiments conducted in vitro [42], but as alluded to earlier, engineering an artificial 
oral microcosm is extremely challenging. While it should be possible to engineer repetitive cycles of $\mathrm{pH}$, solute-solvent combinations, thermal cycling and mechanical loading that generate compressive, tensile and shear stress, other key parameters are the patient's salivary composition and amounts, shifting occlusal loads, dietary habits and oral cleanliness. Emerging research can be interpreted as if even the individual's intra-oral bacterial profile may play a role in the biodegradation of some polymers [43], which is a factor that is very difficult to simulate in a laboratory model [44].

For years, the best practice for dentists with regard to excavation of carious dentin has been to stop when the surface seemed "firm" upon probing with a dull dental probe. Later studies showed that this practice removed the infected dentin, but left a superficial zone of demineralised tissue [45]. Later studies has revealed that carious dentin display four different zones, each zone with distinct microstructure changes, nanomechanical properties and decreasing mineral contents [46]. Efforts to achieve biomimetic remineralization in dentin are ongoing [47], with a major rationale that once the dentin begins to remineralize its biomechanical properties improve [48]. However, the remineralisation of these zones in the dentin is far more complex than in enamel, since there are no seed mineral crystals that remain like in enamel [49].

\section{Diagnosis of secondary caries versus detection of artificial caries-like lesions}

There appears to be confusion about terminology regarding secondary, alternatively labelled as recurrent, caries. In the classic study that firmly linked dental caries to a high consumption of carbohydrates, i.e., the Vipeholm study, secondary caries was simply described as "caries adjacent fillings" [50]. Many today hold the same view, while others have pursued the quest to identify and eliminate so-called "(cavity) wall (caries) lesions", a term that first appeared in the scientific dental literature in 1971 [51]. The labelled lesions observed in the PLM as "caries", in spite of the estimated 1-2\% mineral loss that these lesions represented [52]. In perspective, the body zone of an enamel caries lesion contain between 25 and 50\% mineral loss [13]. Even though minute demineralizations may correctly be labelled as "caries" from a strict scientific perception, most dentists and patients will have a very different mental picture upon discussing the signs and symptoms of the disease entitled "dental caries". 
Uniform terminology is important, and it is likely that researchers and clinicians differ in their concept of perspective of the disease entitled "dental caries" [53], and particularly so to the conception of "secondary caries". Any disease can be regarded from two different concepts of perspective, which have been labelled as essentialistic or nominalistic [54]. The former signifies a conviction that the disease exist in itself, but our criteria for describing the disease changes over time. The alternative perspective is that it is the actual signs and symptoms that constitute the disease. An essentialistic perspective is that (secondary) caries is ubiquitous in all individuals since there is a constant demineralization-remineralization activity process ongoing on the tooth surfaces, including along the restoration margins. It follows that the manifest clinical signs and symptoms is regarded as the consequences of caries and does not constitute the disease in itself. With an essentialistic perspective, any mineral loss from the dental tissues will constitute "caries or secondary caries". The alternative nominalistic perspective is that one or more actual signs constitute "caries or secondary caries", and the question that remains is to define the most appropriate operational thresholds. Some may feel that this threshold is at the lowest detection limit of a particular new high-tech tool that employ, electrical conductivity or computerized radiography. Others may decide that the operational threshold is a white or brown spot on the enamel that is apparent visually or enhanced with some form of light-, infrared- or laser-induced fluorescence. A third threshold level is represented by visually apparent frank cavitation with or without a discoloration or softened tissue upon probing.

The recognition that researchers, clinicians and patients may hold essentialistic or nominalistic perspectives on secondary caries, provides a conceivable framework for interpreting the occasionally incompatible findings and opinions. Stated in other words, one needs to be reminded that there is a vast difference between detecting a particular quantity of demineralization in a sample, versus diagnosing a disease intraorally. Using the label "caries" for both is conceptually inappropriate, and researchers and clinicians should in communications clearly separate between the disease "caries" and the histopathologically term "artificial caries-like lesions".

Most of the techniques used for detecting primary caries and artificial caries-like lesions have also been used to detect secondary caries and artificial caries-like lesions 
adjacent to restorations. There is no particular technique that is only applicable to detect caries adjacent to restorations. The predominant detection method favored in laboratory research appears to be ground sections examined in a PLM or microradiography. Recent research has adopted more modern technologies, principally methods relying on the optical properties of hard tissues. To the author's knowledge, there are no systematic studies on possible artifacts and distortions of different approaches with respect to the detection of secondary caries or artificial caries-like lesions. Such effects may originate from, e.g., optical edge effects, specular reflections from the restoration surface or from organic and inorganic components with particular physico-optical properties.in the tooth-restoration interface.

Dental hard tissues that remain in intimate contact with a restorative material demonstrate often a different optical birefringence compared to the remaining bulk of the tissues. The investigators that first described the phenomenon based on observations in PLM interpreted the areas in the contact zone of the enamel and dentin as caries [51]. They stated further that the areas were often not visible when the ground specimens were imbibed in water, but appeared only when the sections were imbibed in quinoline. Based on this information, the estimated mineral loss would amount to 1-2\%, based on the algorithm available for calculating mineral loss [52]. Intriguingly, all estimate algorithms at the time were based on experiments on enamel and not for dentin, since the whole basis for using combinations of imbibition media with different molecular sizes and refractive indices was to establish molecular sieving as a function of pore sizes in the enamel $[11,12]$. Given more recent adjustments on the relationship between optical birefringence and mineral content in enamel [14], as well identified polynomial relationships of the non-mineral contents as a function of the mineral content [55] one may doubt that even the estimated 1-2\% mineral loss is correct. Appraisal of the optical birefringence of dental tissues in PLM is influenced by many known and probably unknown variables, including the strong effects of extraction of lipid and protein and likely other organic substances on optical birefringence [56]. One team of investigators have even questioned whether estimates of mineral content in dentin based on PLM have been correctly interpreted over the years [57]. 
Quantitative light-induced fluorescence (QLF) has been appraised in eight clinical studies for diagnosing secondary caries or detecting artificial caries-like lesions adjacent to restorations [58]. Only one study describe the tool as better than the use of radiographic bitewing films or visual examinations [59], while the remaining papers suggest that the technology should at best be considered as complimentary.

OCT has been used to detect artificial caries-like lesions below fissure sealants [60], and may have promise for use as a tool for diagnosing secondary caries beneath translucent restorative materials when combined with cross-polarization (PS-OCT) and Fourier-domain techniques (so-called Swept-source OCT) using near-infrared light [61]. However, it remains to be resolved how to proceed in practice to take into account the vast variation of refractive indices of different resin composites as a function of their filler content and particle size distributions [62].

\section{Etiological factors}

Secondary caries may develop rapidly around and below a broken restoration, or slower and more localised on the enamel along the cavosurface margin. Some will also advocate the existence of a third type, labelled as "(cavity) wall caries", which will be discussed in the following sections. There are no reliable estimates of the prevalence, nor proportions of the three types of secondary caries development, but the localized type likely predominates [63].

Any site along the cavosurface margin will demineralise if the local conditions change to an acidic environment. In this regard, secondary caries is not different from primary caries, although the demineralization-remineralization process is influenced also by the presence of fluorides, if any. The acidic environment depend on the biomass of specific cariogenic bacteria on the more or less polished restoration surface, or rather to the intermediary salivary glycoproteins that first form a pellicle to this surface [64]. A minimum critical amount of mature biofilm is required to create the acidic environment, and there are few alternative hypotheses regarding the origin of the acidic environment. A general belief is that the cariogenic biofilm for primary and secondary caries are similar, and consist mainly of Streptococcus mutans, Lactobacilli and Actinomyces 
naeslundii [65-67], although a contrary opinion based on observations made in an in situ experiment has been proposed [68].

All factors that enhance the accumulation of biofilm mass or impede biofilm removal may be considered as risk factors for secondary caries. It is probably the reason why secondary caries occurs predominantly cervically, and especially on the proximal surfaces [69].

The qualities and quantity of biofilms on restorative materials have been measured after some time on specimens appraised in vitro, alternatively in situ in a dental device, or collected on surfaces of restorations in vivo. Differences have been noted, as expected due to variance of surface roughness and porosities as well as variance of physicochemical properties. It is imperative to recognize that the bacterial colonisation of pellicle-coated surfaces under in vivo conditions differs considerably from monospecies or multispecies biofilm models in vitro. Moreover, corrosion- and biodegradation products originating from the restorative material may influence the biofilm [70], and the association between surface topography and chemistry and biofilm quantity and qualities is complex and not yet fully understood [71]. No research has addressed whether particular corrosion- and biodegradation products may be associated with the bacterial composition of infected dentinal secondary caries lesions. Infected dentin at the enamel-dentin junction that originate from secondary caries appear to have similar microflora as if the origin was primary caries, consisting of anaerobic microflora, Streptococcus mutans and Lactobacilli [72]. It is unclear, whether infected dentinal caries adjacent to restorations made from amalgam versus resin composite may differ. One research group proposed that the amount of microorganisms under composite compared to amalgam was higher and with a greater variety [73], while another group reported no such differences [74].

An individual's risk for secondary caries is also modified by the saliva quantity and qualities, which in particular comprise the salivary buffering ability. Patients with xerostomia for whatever reason experience more secondary caries, as a reflection of a higher risk of all forms of caries. 
With regard to adaptation at the cavosurface margin there is likely a correlation between larger and larger defects or gaps versus bulk of accumulated biofilm and consequently a risk of secondary caries, but it is impossible to determine a "minimum size". An adaptation between a restoration and a tooth at the cavosurface margin is generally considered clinically acceptable when it is less than about $30 \mu \mathrm{m}$, even though this leaves more than enough space for ingrowth of bacteria that have a dimension of about one $\mu \mathrm{m}$.

Nobody has persuasively documented clinically that caries can develop in a toothrestoration interface independent of enamel caries on the outer surface [63]. In contrast, restored teeth with secondary caries often reveal lesions on the outer enamel surface that are unrelated to the tooth-restoration interface [75]. Nor is there any evidence that localized caries in the tooth-restoration interface can progress along the enamel-dentin junction beyond the periphery of the body zone of the enamel caries.

In conclusion, secondary caries may develop in the presence of a cariogenic biofilm, but it will probably never develop in lack of a cariogenic biofilm regardless of the technical quality of the restoration. A discussion of which particular detail of the restoration that represent a threshold between a minor and major risk for secondary caries development appears from this perspective to be indeterminate. The oral hygiene habits of the patient is the primary factor that determines if secondary caries develops, not whether the restoration along the cavosurface margin can be considered as 'excellent', 'adequate' or 'deteriorated'.

\section{The "(cavity) wall lesion" - what is in a word?}

The term "wall lesion" including its variants is ill defined, has been, and is still being used indiscriminately. Variants are e.g., "inner (wall) caries like lesion" [77] and "secondary caries wall lesion" [78]. Firstly, as argued in a previous section there is a difference between an artificially created "caries-like lesion" characterized by a certain level of demineralization, versus the disease entitled "caries". Secondly, as discussed below it is doubtful whether there is an entity such as a wall lesion that exists independent of an outer enamel lesion. Thirdly, it is important to realize that the connotation of the term varies in the literature. The majority of research papers use the 
term "wall lesion" simply to describe the portion of a caries lesion or artificially created caries-like lesion that is in contact with a restoration. However, some investigators have also used the term to describe the surface of tooth specimens placed against a block of restorative material and exposed to an acidic environment $[77,78]$.

The term originated in the scientific dental literature from a paper describing the histopathological characteristics of dental tissues adjacent to amalgam restorations that had been exposed to a very aggressive chemical environment for extensive periods [51]. The investigators reported that "wall lesions" appeared as a narrow zone with a uniform thickness along the tooth-restoration interface when ground sections were imbided in quinolone and viewed in PLM.

While there is no reason to doubt that something was observed in the PLM, a lingering question is whether not the optical phenomenon observed by these [51] and subsequent investigators could have different explanations besides an estimated minuscule demineralization [52] along the tooth-restoration interface. Apatite is a very reactive mineral that can undergo rapid chemical substitutions, which slightly changes the mineral structure and often have critical effects on optical properties such as birefringence [79]. While fluorapatite has a optical birefringence of 0.003 , hydroxapatite range between 0.004 and 0.007 , but even minor changes of e.g., carbonate levels have a pronounced effect on optical birefringence [80].

It would seem reasonable to assume that a machined or chemically primed enamel or dentinal surface, such as a cavity wall, would display a different optical birefringence compared to the bulk tissue. In fact, one investigator reported also "wall lesions" along the pulpal floor of prepared cavities that had remained unrestored and contained only in water [52]. Unfortunately, the author failed to discuss this particular finding and later investigators seem not to have repeated the efforts of making control specimens made from cavity-prepared, but unrestored teeth.

Moreover, the investigators hypothesized that the "wall lesion" was most likely caused by hydrogen ions penetrating from the outer surface through the tooth-restoration interface referred to as a "microspace" [51]. However, the hypothesis seems questionable since this should have caused relatively more demineralization near the 
outer surface and relatively less in the pulpal direction where calcium and phosphates would rapidly supersaturate the fluid and counter-effect any hydrogen penetrating only in the tooth-restoration interface starting from the surface. Examination of multiple articles that present PLM photographs reveal no funnel-like lesions in the dental contact zone along any restorations. Interestingly, one of the main conclusions in the paper that first described the histopathological characteristics of the dental tissues adjacent to restorations was that the "wall lesions" were more extensive under unsupported in comparison with supported enamel prisms [51]. To this author's knowledge there has not been subsequent research to clarify this aspect, nor to the other piece of information in the original paper that the enamel under unsupported prisms was actually radiopaque in the immediate contact zone and otherwise radiolucent, which the authors attributed to reprecipitation of reaction products. Hence, it seems more likely that the etiopathogenesis of these caries-like lesions adjacent to restorations is predominantly analogous to how caries-like lesions develop in enamel, where an exchange of hydrogen and dissolved calcium and phosphate occurs along the enamel prisms. This hypothesis is not in contradiction with the possibility that once the demineralization along the nanometer size enamel prisms conjoin with the tooth-restoration interface, the scale of exchange of ions multiplies due to larger surface area and facilitated transport through a larger volume of fluid in the micrometer size interface.

A contributing factor for the observed optical phenomena in the initial study on amalgam restorations [51] were likely also the effects of aqueous metal salt solutions and sulphides that rapidly would have started to accumulate in the tooth-restoration interface and infiltrated the superficial layers of the hard tissues. Aqueous metal salt solutions influence optical birefringence [80]. The investigators themselves identified high concentrations of zinc and tin in the wall lesions with the use of electron probe analyses, and proposed that the presence of the ions was likely due to corrosion [81]. There are indicators that there is an association between corrosion properties as a function of amalgam alloy composition and extent of "wall lesions" [82]. It appears illogical that the artificially created caries-like "wall lesions" are seldom observed for restorations made from non-metallic materials, unless corrosion is not a major etiological component. 
In general, several of the approaches used to generate artificial caries-like lesions are very aggressive. Remarkably little discussion has evolved about how these aggressive approaches create microenvironments that do not occur in reality. For metallic restorations, it is likely that spontaneous active crevice corrosion develop, that further lowers the local $\mathrm{pH}$ [83]. The most thermodynamically active components that penetrate and precipitate in the dentin is tin and zinc, and the main corrosion constituent in toothrestoration interfaces including in dentinal cavity walls has been identified as oxides, sulphides and chlorides of tin, and to a lesser extent zinc and copper [84, 85]. Under which circumstances the metallic ions are transported superficially, or alternatively penetrate and precipitate deeper into the dentin remains unclear [86]. Moreover, systematic studies on the likely effects on change of optical birefringence $[79,80]$ upon penetration of metallic ions into dental tissues are lacking.

With regard to polymeric materials and associated cavity preparations it is well known that even a short cavity etching procedure creates a zone of altered optical birefringence or "wall lesion" upon subsequent examination in a PLM [87]. The reason is unclear, but dentin demonstrates form bifringence, which has been attributed to the micrometer size of the dentin tubules [88]. Moreover, collagen, which is abundant in dentin also displays form birefringence [89]. It is not unlikely that any or all of these confounders will cause or influence optical birefringence in the interface between a restoration and tooth when ground sections are observed in a PLM [57].

\section{Etiopathogenesis of secondary caries gained from in vitro research}

The current knowledge about etiopathogenesis of secondary caries is gained essentially from in vitro experiments and clinical in situ models (Figure 2). In vitro experiments in the laboratory cover studies on microleakage or artificial caries-like lesions adjacent to restorations, and a few studies that include both. Laboratory tests designed to predict clinical outcomes must rely on sound data on actual clinical performance obtained through controlled studies or evaluations [90, 91]. An example where controversy has existed due to the incongruence between the predominantly encouraging in vitro data and the less impressive in vivo results is the alleged benefits of glass ionomer cement with regard to secondary caries $[92,93]$. One study that sought to clarify the relationship 
between artificially created caries-like lesions adjacent to restorations with secondary caries concluded that there was a complete lack of correlation [94]. The investigators stated further that they believed artificial caries-like lesions created in the laboratory have a negligible clinical relevance in predicting caries of fluoride-containing materials, a sentiment that have also been expressed by others [95, 96]. Yet, other investigators have continued to present study findings from in vitro experiments claiming alleged protective effect of fluorides from glass-ionomer cement [97, 98].

\subsection{Microleakage}

The investigators who proposed the term "wall lesion" proposed also an association with a "microspace" between the tooth and the restoration [51]. Many still believe that such tooth-restoration "microspaces" exist where secondary caries can progress to frank cavitation, independent of any enamel caries, and that microleakage studies attest to the existence of this "weak link". It is probably not the case.

A key publication that prompted great interest on the subject contained the provocative title "Fluid exchange at the margins of dental restorations" [99]. The authors reported that droplets with a diameter up to $44 \mu \mathrm{m}$ developed along the restoration cavosurface margins in extracted teeth upon rapidly freezing and thawing. The authors dubbed the phenomenon as "marginal percolation" attributed to differences in thermal expansion of the tooth and the restorative material [99]. Almost concurrently, it was discovered that dental structures were permeable to radioisotopes, which included the "penetration at margins" [100]. Contemporary research literature reported on the "sealing qualities or properties" of restorative materials, with the objective to obtain "hermetic sealing" and avoid "fluid penetration". The term "marginal leakage" appeared a few years later in 1961 [101]. The catchy term "microleakage", which has remained to this day and suppressed all preceding descriptors, appears in a few IADR meeting abstracts from 1959, but the first actual article containing the term was published in 1966 [102]. The derivative term "nanoleakage" appeared some 30 years later, to denote localized leakage within the tooth-adhesive interface [103], although the $50 \mathrm{wt} \%$ silver nitrate that is used as a marker by then had already been used in microleakage experiments for a decade [104]. 
Microleakage experiments apparently continue to emerge regardless of multiple reviews over the last 20 years questioning the reliability and validity of the experimental materials and methods (Table 1). Despite appeals from journal editors and some researchers to advance the methodology of microleakage experiments, rather than reporting more data, relatively few papers describe the effects of experimental variables on the outcomes [4-10]. As a consequence, there are great variations in experimental setups [116-117], to the extent that it is seldom possibility to meta-analyse any results [115]. Besides the still unknown confounders, numerous variables influence the microleakage experiment outcomes [7-10]. Examples are the source and type of teeth or tooth specimens, and choice of storage substrate and -time. An additional variable is the type of intra- or extra-coronal restoration, including the location of the cavosurface margin and angulation of cavity walls [119]. The handling, placement technique and polishing of the restorative material also influence the extent of observable microleakage $[9,10]$. There is no consensus on consistency for multiple variables known to influence results, such as standardized aging processing like thermocycling [120], pH cycling [121] or repetitive mechanical loading [122]. Nor does this pertain to temperature and relative humidity during the conduct of the experiments [123]. The characteristics of the dye or tracer, such as its diameter, and the chemical properties of the solute and solvent as a function of concentrations and exposure time appears also to play a central role [116-118]. Most tracers have molecular radius of less than one nm, and it is not improbable that the microleakage in many cases is simply a manifestation of capillary action phenomena. The minuscule molecular dimension of dyes allows penetration into inter- and intraprismatic micropores in enamel considered to be1-30 nm wide, as well as in the peri- or intertubular dentin having 0.8-2.5 $\mu \mathrm{m}$ wide dentinal tubules. The use of fluorescent compounds have expanded the possibilities to appraise microleakage "bidirectionally" [124], but the confounding variables remain as a methodological challenge.

Finally, there is variation with regard to the detection method, which is most often optical, and whether estimates of microleakage are based on two-dimensional appraisal or some form of volumetric measurements. Non-destructive tools that can provide volumetric estimates include confocal microscopy for relatively translucent materials 
[125], CLSM [126], $\mu \mathrm{CT}$ [127] and OCT used with or without an additional contrast solution [128-130]. So far, the methods have been used to appraise sizes of gaps and defects, but not to experiments combining microleakage and creation of artificial carieslike lesions.

On top of all the critical opinions of microleakage experiments (Table 1), allegations have also been forwarded that many publications on microleakage contain incorrect statistical estimates and presentations [131, 132]. The lingering question in light of all this criticism is why so many still persist on conducting microleakage experiments and publish their data. In this light it is intriguing that most, but not all, conclusions made from microleakage experiments appear to be more often than not in harmony with clinical observations (Table 2).

Most microleakage experiments have been done on extracted human teeth or bovine teeth. However, an alternative approach has been to restore teeth in situ, using either a permanent tooth meant for extraction, usually for orthodontic indications or in a deciduous tooth soon to be exfoliated. The time before extraction has varied from 7 days [133], 4 to 6 weeks [134], to 5 to 7 weeks [135], or up to 18 months for exfoliated primary molars $[136,137]$. In general, the conclusions made from these studies do not deviate from the observations made in the laboratory experiments. Nevertheless, subjecting extracted restored teeth subsequently to microleakage experiments is questionable, since high tensile and shear forces are generated during the extraction process that entail high risks of causing structural damage that is not necessarily visually apparent.

\subsection{Artificial caries-like lesions adjacent to restorations}

Since the first description of an experimental setup for developing artificial-like lesions adjacent to restorations in 1967 [138], some 160 reports have been published predominantly related to fluoride-containing materials. The number of experimental variables are at least as extensive as for the microleakage experiments. Acidified gelatin developed for generating artificial caries-like lesions in enamel was favored throughout the seventies and early eighties, and restored teeth were exposed to the acidified media for up to 200 days [51]. Acidified broths were also adopted by some 
research groups, predominantly inoculated with Streptococcus mutans and sucrose. Whole teeth were restored, alternatively tooth specimens fabricated from human or bovine teeth and placed either immediately, alternatively after some form of artificial aging in closed vials, tubes or chambers. The acidified media were replenished in some studies, but the intervals have varied. Buffered media and less aggressive corrosive models appeared once glass-ionomer cements and other fluoride-containing restorative materials were subjected to studies on the relationship between fluoride release and remineralization [34, 95]. In some studies, the acidified gels were dialyzed to eliminate ionically active calcium, phosphate and fluoride to assess only the fluoride release from the restorative material.

Apart from the focus on material composition and fluoride release, several investigators have attempted to establish the relationship between artificial caries-like lesions and possible influence of the marginal gap size. In one early study, the investigators immersed specimens of human teeth in a broth inoculated with Streptococcus mutans containing either sucrose or glucose. The specimens were mounted in a mechanical screw device that enabled the placement of tooth block containing both enamel and dentin to be located at a specific distance from a block made from amalgam. Abundant amounts of biofilm developed on all surfaces. Artificial caries-like lesions could be observed consistently in the contact zone of the dentin regardless of the gap space, but seldom in the contact zone of the enamel. The enamel surface that did not face the amalgam block developed extensive artificial caries-like lesions under an a thick layer of biofilm [139].

This geometric setup was replicated in an improved mechanical device several years later against a block of resin composite [140]. The authors concluded that there were clear correlations between gap size and demineralized lesions in the contact zone, which they regrettably named "wall lesion". They reported also that artificial caries-like lesions could be observed at "gap size zero", although they cautioned about the limitations of the model and need to be careful in drawing clinical implications from their findings. Using the same device, other investigator groups have replicated the geometric setup and consistently described the demineralization occurring on the side of the specimen facing the block of restoration materials and regrettably stuck with the 
term "wall lesion" [77, 78]. E.g., in one of the studies a specimen block was covered with an acid-resistant varnish leaving only one surface, i.e. "the wall", some 50 to $250 \mu \mathrm{m}$ away from a block of resin composite and place the assembly in an acidic environment [77]. Obviously, one would expect demineralization to occur, but complete misunderstanding of the results by clinicians because of poor choices of terminology by basic scientists is understandable upon reading conclusions such as: "The extent of independently developed wall lesions increased with gap width in the present setting" [77].

Dental hard tissues including the tooth-restoration interface contain mineral, structural and adsorbed water and organic matter that undergo dynamical changes during the deand remineralization progressive steps in different histological layers. A problem with many of the in vitro models is that the remineralization potential is limited. Moreover, the medium needs to be replenished regularly to avoid stagnation and buildup of acids or ions, including fluorides, which may control reactions. Another clinically relevant factor that is seldom incorporated into in vitro experiments is the effects of mechanical loading, which clearly affects the tooth-restorations negatively and accelerates the rate of artificial caries-like lesions $[122,141]$.

Some investigators have attempted to overcome the methodological problems with in vitro experiments by conducting in situ experiments. Approximately $1 \times 2 \times 1.5 \mathrm{~mm}$ tooth specimens adjoined with same size restorative materials have been mounted in an intraoral device $[142,143]$ or a complete removable prosthesis [144] and worn for several weeks. Demineralization has been speeded up by washing the device in a sucrose solution. The authors name these demineralized contact zones as "wall lesion"[144] or "secondary caries"[143] or "secondary caries lesion"[142], all terms that may be questioned given the arguments presented in previous sections of this review. In summary, several of the in vitro and in situ approaches to create artificial caries-like lesions have been applied to generate artificial caries-like lesions adjacent to restorations. However, to what extent the different approaches vary with regard to type and extent of deterioration of different restorative materials and adhesives has not been systematically examined and reported. It is very likely that the various techniques for 
creating artificial caries-like lesions will cause different interactions with the actual restorative material or tooth-restoration interface. One study reported that a chemical method was more aggressive than a microbial approach applied to six different groups of restorative materials [145].

That the major bulk of dentinal caries is heavily infected and not only demineralised is difficult to simulate in a laboratory experiment. While this factor may perhaps not be significant when the research focus is demineralization-remineralization of primary caries, the situation is different with regard to the study of the etiopathogenesis secondary caries. One of the hypothetical benefits of leakage of, e.g., antibacterial agents in adhesives, fluorides from glass-ionomer cement or zinc from amalgam is the conceivable bactericidal or bacteriostatic effects. One may perhaps better understand the complexities of unknown variables when realizing that e.g., the desirable release of fluoride ions from a fluoride-containing material is a consequence of basically corrosion or degradation, which is only desirable up to a certain extent. E.g., for amalgams the selected approach to create artificial caries-like lesions adjacent to restorations will impact on how rapidly stannous- and zinc oxides and -sulphides will develop, which eventually obliterate the microspace, but will at the same time also reduce the leakage of fluoride ions. Another effect associated with the corrosion of amalgam that is difficult, if not impossible to study in any existing techniques to create artificial caries-like lesions is the effect of leaked zinc ions that promote the formation of apatite crystals on partially demineralized collagen fibrils and thereby induce remineralization of dentin interfaces [146]. In summary, it is not obvious that techniques to create artificial caries-like lesions developed for the study of etiopathogenesis of enamel caries are also appropriate for elucidating etiopathogenesis of secondary caries.

\section{Secondary caries incidence in controlled clinical studies versus cross-sectional examinations}

Reports of the incidence as well as the prevalence of secondary caries have ranged from insignificant to extensive and multiple authors have voiced scepticism with regard to their validity in both directions [1-3, 147-149]. Which estimates of secondary caries should we believe? The list of potential biases that likely influences the estimates is 
extensive and includes selection bias, performance bias, detection or assessment bias, attrition bias and reporting bias. Respective typical examples are patient recruitment amongst dental students; studies not conducted in general dental practice, lack of operational descriptive criteria or judgement of own clinical work; high number of patient dropouts especially amongst the unhappy ones; and the reporting of surrogate or alternative outcomes rather than patient-relevant ones [147, 148].

At what stage the attrition rate becomes a concern with regard to restoration performance estimates is uncertain. As for all categories of clinical research, a balance needs to be sought between maintaining methological rigor versus practicality. One author group defined trials with low methodological quality as non-RCT or RCT with more than 5\% participant attrition per year [149], which disqualifies an estimated $98 \%$ of all publications today. Probabilistic logic aside, it can be countered-argued that in today's mobile world, the likelihood of a near-zero attrition is unrealistic. It follows that study participants who return for a follow-up clinical examination many years after the initial restorative treatment for a particular reason are perhaps not representative of the general population at large, at least not when it comes to oral health attitudes and treatment behavior. A concern of patient representability can be also be applied to retrospective clinical studies. The moment a decision is made to recall patients for whatever research objective to combine observations with information in the patient charts, it is the happy patients that have remained in the practice, while the dissatisfied ones have disappeared.

In conclusion, the data sampling method, patient demography as well as study methodology influence the incidence and prevalence estimates of secondary caries. It may be questioned whether a quest for "overall" exact values are meaningful from a scientific or clinical perspective.

It is taken for granted that dentists in real-life prepare textbook-like cavities in teeth to receive the restoration. Is this a correct assumption? The quality of cavity preparations made by dentists to receive restorations has received scant attention in the literature. With the use of a comprehensive set of criteria for the assessment of class II cavities [150], it was recognized that a large proportion of such cavities prepared by dentists in a 
practice base research network contained multiple deviations from the textbook "ideal" morphology [151-154]. However, the impact of questionable and inadequate cavity preparations on the incidence of secondary caries was minor with regard to class II restorations made from amalgam when these were monitored over the following ten years [155-156]. Whether this would have been the case for posterior resin composite restorations is left to the qualified reader to consider. The knowledge that was gained in this study though, is that the assumption that all dentists in real/life dentistry consistently prepare ideal textbook-like cavities is incorrect. It is likely also naïve to believe that dentists always handle and place restorative materials optimally and according to handling instructions and ensure that their patient is motivated and able to prevent future caries. Data on restoration performance obtained in cross-sectional studies reflect the good and the bad operators and oral health attitudes and practices of patients. Conversely, results from clinical trials conducted under strictly controlled and monitored conditions where calibrated and highly technically skilled clinicians place restorations in teeth of e.g., dental faculty and students in a clinical setting with no support staff and time constraints have perhaps more value for the manufacturers' marketing departments than for their colleagues working in the research and development departments. Restorations undoubtedly perform better than average when placed in such exceptional circumstances, and results may be considered as a best performance potential in patients with excellent oral health. However, results based on clinical work in settings where cost per unit time is of nominal concern do not provide any indications on how the restorative material will perform when placed by the average dentists in mouths of their spectrum of patients during a busy workday. Stakeholders have raised a reasonable concern about whether manufacturers should devote more time and effort to develop restorative materials that perform adequately in the hands of most professionals or optimal performance in the hands of only the highly skilled professionals [157]. 


\section{References}

1. Mjör IA, Jokstad A, Qvist V. Longevity of posterior restorations. Int Dent J, 1990; 40:11-17.

2. Jokstad A, Bayne S, Blunck U, Tyas M, Wilson N. Quality of dental restorations. FDI Commission Project 2-95. Int Dent J, 2001; 51:117-158.

3. Demarco FF, Correa MB, Cenci MS, Moraes RR, Opdam NJ. Longevity of posterior composite restorations: not only a matter of materials. Dent Mater, 2012; 28:87-101.

4. Heintze SD. Systematic reviews: I. The correlation between laboratory tests on marginal quality and bond strength. II. The correlation between marginal quality and clinical outcome. J Adhes Dent, 2007; 9 Suppl 1:77-106.

5. Heintze SD, Zimmerli B. Relevance of In vitro tests of Adhesive and Composite dental materials. A Review in 3 Parts. Part 3: In vitro tests of adhesive systems. Schweiz Monatsschr Zahnmed, 2011; 121:1024-1040.

6. Bayne SC. Correlation of clinical performance with 'in vitro tests' of restorative Dent Mater, that use polymer-based matrices. Dent Mater, 2012; 28:52-71.

7. Dennison JB, Sarrett DC. Prediction and diagnosis of clinical outcomes affecting restoration margins. J Oral Rehabil, 2012; 39:301-318.

8. Heintze SD. Clinical relevance of tests on bond strength, microleakage and marginal adaptation. Dent Mater, 2013; 29:59-84.

9. Dietschi D, Argente A, Krejci I, Mandikos M. In vitro performance of Class I and II composite restorations: a literature review on nondestructive laboratory trials--part I. Oper Dent, 2013; 38:166-181.

10. Dietschi D, Argente A, Krejci I, Mandikos M. In vitro performance of Class I and II composite restorations: a literature review on nondestructive laboratory trials--part II. Oper Dent, 2013; 38:182-200.

11. Darling Al. Studies of the early lesion of enamel caries. Br Dent J, 1958; 105:119135.

12. Darling Al, Mortimer KV, Poole DF, Ollis WD. Molecular sieve behaviour of normal and carious human dental enamel. Arch Oral Biol, 1961; 5:251-273.

13. Robinson C, Shore RC, Brookes SJ, Strafford S, Wood SR, Kirkham J. The chemistry of enamel caries. Crit Rev Oral Biol Med, 2000; 11:481-495. 
14. Theuns HM, Shellis RP, Groeneveld A, Van Dijk JWE, Poole DFG. Relationships between birefringence and mineral content in artificial caries lesion of enamel. Caries Res, 1993; 27:9-14.

15. Shellis RP. A scanning electron-microscopic study of solubility variations in human enamel and dentine. Arch Oral Biol, 1996; 41:473-484.

16. Mjör IA. Chapter 4. Dental caries: Characteristics of lesions and pulpal reactions. In:Pulp-dentin biology in restorative dentistry. Mjör, IA (ed). Illinois: Quintessence Publishing Inc; 2002.

17. Tay FR, Messer H, Schwartz R. Chapter 14. Caries, Restorative Dentistry, and the Pulp. In: Seltzer and Bender's Dental Pulp. Hargreaves, KM, Goodis HE, Tay F (eds), Second Edition. Illinois: Quintessence Publishing Inc; 2012.

18. Bjørndal L, Thylstrup A. A structural analysis of approximal enamel caries lesions and subjacent dentin reactions. Eur J Oral Sci, 1995; 103:25-31.

19. Wefel JS, Heilman JR, Jordan TH. Comparisons of in vitro root caries models. Caries Res, 1995; 29:204-209.

20. Silverstone LM. The surface zone in caries and in caries-like lesions produced in vitro. Br Dent J, 1968; 125:145-157.

21. Featherstone JD, Duncan JF, Cutress TW. A mechanism for dental caries based on chemical processes and diffusion phenomena during in-vitro caries simulation on human tooth enamel. Arch Oral Biol, 1979; 24:101-112.

22. Ten Cate JM, Duijsters PP. Alternating demineralization and remineralization of artificial enamel lesions. Caries Res, 1982; 16:201-210.

23. Sissons $\mathrm{CH}$. Artificial dental plaque biofilm model systems. Adv Dent Res, 1997; 11:110-126.

24. Wimpenny JW. The validity of models. Adv Dent Res, 1997; 11:150-159.

25. Tang G, Yip HK, Cutress TW, Samaranayake LP. Artificial mouth model systems and their contribution to caries research: a review. J Dent, 2003; 31:161-171.

26. Zero DT. In situ caries models. Adv Dent Res, 1995; 9:214-230.

27. ten Cate JM. In situ models, physico-chemical aspects. Adv Dent Res, 1994; 8:125133.

28. Arends J, Dijkman T, Christoffersen J. Average mineral loss in dental enamel during demineralization. Caries Res, 1987; 21:249-254. 
29. Manson-Hing LR, Keller SE, Feagin FF, Koulourides T. Microradiographic Comparison of Artificial Caries Systems. J Dent Res, 1972; 51:923-928.

30. Magalhaes AC, Moron BM, Comar LP, Wiegand A, Buchalla W, Buzalaf MA. Comparison of cross-sectional hardness and transverse microradiography of artificial carious enamel lesions induced by different demineralising solutions and gels. Caries Res, 2009; 43:474-483.

31. Moron BM, Comar LP, Wiegand A, Buchalla W, Yu H, Buzalaf MA, Magalhaes AC. Different protocols to produce artificial dentine carious lesions in vitro and in situ: hardness and mineral content correlation. Caries Res, 2013; 47:162-170.

32. Wilkinson SC, Higham SM, Ingram GS, Edgar WM. Visualization of root caries lesions by means of a diazonium dye. Adv Dent Res, 1997; 11:515-522.

33. Arends J, Ruben JL, Inaba D. Major topics in quantitative microradiography of enamel and dentin: $\mathrm{R}$ parameter, mineral distribution visualization, and hyperremineralization. Adv Dent Res, 1997; 11:403-414.

34. Featherstone JD. Modeling the caries-inhibitory effects of dental materials. Dent Mater, 1996; 12:194-197.

35. Arends J, Ruben JL, Christoffersen J, Jongebloed WL, Zuidgeest TG. Remineralization of human dentine in vitro. Caries Res, 1990; 24:432-435.

36. Ten Bosch JJ, Angmar-Månsson B. Characterization and validation of diagnostic methods. Monogr Oral Sci, 2000; 17:174-189.

37. Wang XJ, Milner TE, de Boer JF, Zhang Y, Pashley DH, Nelson JS. Characterization of dentin and enamel by use of optical coherence tomography. Appl Opt, 1999; 38:2092-2096.

38. Fried D, Featherstone JD, Darling CL, Jones RS, Ngaotheppitak P, Bühler CM. Early caries imaging and monitoring with near-infrared light. Dent Clin North Am, 2005; 49:771-793.

39. Spencer P, Ye Q, Misra A, Goncalves SE, Laurence JS. Proteins, pathogens, and failure at the composite-tooth interface. J Dent Res, 2014; 93:1243-1249.

40. Cai K, Delaviz Y, Banh M, Guo Y, Santerre JP. Biodegradation of composite resin with ester linkages: identifying human salivary enzyme activity with a potential role in the esterolytic process. Dent Mater, 2014; 30:848-860. 
41. Delaviz Y, Finer Y, Santerre JP. Biodegradation of resin composites and adhesives by oral bacteria and saliva: a rationale for new material designs that consider the clinical environment and treatment challenges. Dent Mater, 2014; 30:16-32.

42. Lohbauer U, Belli R, Ferracane JL. Factors involved in mechanical fatigue degradation of dental resin composites. J Dent Res, 2013; 92:584-591.

43. Bourbia M, Ma D, Cvitkovitch DG, Santerre JP, Finer Y. Cariogenic bacteria degrade dental resin composites and adhesives. J Dent Res, 2013; 92:989-994.

44. Li Y, Carrera C, Chen R, Li J, Lenton P, Rudney JD, Jones RS, Aparicio C, Fok A. Degradation in the dentin-composite interface subjected to multi-species biofilm challenges. Acta Biomater, 2014; 10:375-383.

45. Fusayama T, Terachima S. Differentiation of two layers of carious dentin by staining. J Dent Res, 1972; 51:866.

46. Pugach MK, Strother J, Darling CL, Fried D, Gansky SA, Marshall SJ, Marshall GW. Dentin Caries Zones: Mineral, Structure, and Properties. J Dent Res, 2009; 88:71-76.

47. Cao CY, Mei ML, Li QL, Lo EC, Chu CH. Methods for biomimetic remineralization of human dentine:a systematic review. Int J Mol Sci, 2015; 16:4615-4627.

48. Bertassoni LE, Habelitz S, Kinney JH, Marshall SJ, Marshall GW Jr. Biomechanical perspective on the remineralization of dentin. Caries Res, 2009; 43:70-77.

49. Niu LN, Zhang W, Pashley DH, Breschi L, Mao J, Chen JH, Tay FR. Biomimetic remineralization of dentin. Dent Mater, 2014; 30:77-96.

50. Gustafsson BE, Quensel CE, Lanke LS, Lundqvist C, Grahnen H, Bonow BE, Krasse B. The Vipeholm dental caries study; the effect of different levels of carbohydrate intake on caries activity in 436 individuals observed for five years. Acta Odontol Scand, 1954; 11:232-264.

51. Hals E, Nernaes A. Histopathology of in vitro caries developing around silver amalgam fillings. Caries Res, 1971; 5:58-77.

52. Grieve AR. The occurrence of secondary caries-like lesions in vitro. The effect of a fluoride cavity liner and a cavity varnish. Br Dent J, 1973; 134:530-536.

53. Baelum V, Heidmann J, Nyvad B. Dental caries paradigms in diagnosis and diagnostic research. Eur J Oral Sci, 2006; 114:263-277.

54. Scadding JG. Essentialism and nominalism in medicine: logic of diagnosis in disease terminology. Lancet, 1996; 348(9027):594-596. 
55. Sousa FB, Vianna SS, Santos-Magalhaes NS. Dental enamel birefringence for a wide mineral content range and for different immersion media's refractive indexes: an improved mathematical interpretation, J Microsc, 2009; 233:1.

56. Shellis RP, Hallsworth AS, Kirkham J, Robinson C. Organic material and the optical properties of the dark zone in caries lesions of enamel. Eur J Oral Sci, 2002; 110:392395.

57. Silva PF, de Holanda Ferreira DA, Meira KR, Forte FD, Chaves AM, de Sousa FB. Dentin reactions to caries are misinterpreted by histological "gold standards". F1000Res, 2014; 3:13.

58. Nokhbatolfoghahaie H, Alikhasi M, Chiniforush N, Khoei F, Safavi N, Yaghoub Zadeh B. Evaluation of Accuracy of DIAGNOdent in Diagnosis of Primary and Secondary Caries in Comparison to Conventional Methods. J Lasers Med Sci, 2013; 4:159-167.

59. Neuhaus KW, Rodrigues JA, Seemann R, Lussi A. Detection of proximal secondary caries at cervical class II-amalgam restoration margins in vitro. J Dent, 2012; 40:493499.

60. Jones RS, Staninec M, Fried D. Imaging artificial caries under composite sealants and restorations. J Biomed Opt, 2004; 9:1297-1304.

61. Simon JC, Lucas S, Lee R, Darling CL, Staninec M, Vanderhobli R, Pelzner R, Fried D. In vitro near-infrared imaging of natural secondary caries. Proc SPIE Int Soc Opt Eng, 2015; 9306.

62. Lammeier C, Li Y, Lunos S, Fok A, Rudney J, Jones RS. Influence of dental resin material composition on cross-polarization-optical coherence tomography imaging. J Biomed Opt, 2012; 17:106002.

63. Mjör IA, Toffenetti F. Secondary caries: a literature review with case reports. Quintessence Int, 2000 31:165-179.

64. Song F, Koo H, Ren D. Effects of Material Properties on Bacterial Adhesion and Biofilm Formation. J Dent Res, 2015; 94:1027-1034.

65. Fitzgerald RJ, Adams BO, Davis ME. A microbiological study of recurrent dentinal caries. Caries Res, 1994; 28:409-415.

66. Gonzalez-Cabezas C, Li Y, Gregory RL, Stookey GK. (1999). Distribution of three cariogenic bacteria in secondary carious lesions around amalgam restorations. Caries Res, 1999; 33:357-365. 
67. Gonzalez-Cabezas C, Li Y, Gregory RL, Stookey, GK. Distribution of cariogenic bacteria in carious lesions around tooth-colored restorations. Am J Dent, 2002; 15:248251.

68. Thomas RZ, van der Mei HC, van der Veen MH, de Soet JJ, Huysmans MCDNJM. Bacterial composition and red fluorescence of plaque in relation to primary and secondary caries next to composite: an in situ study. Oral Microbiol Immunol, 2008; 23:7-13.

69. Mjör IA. Frequency of secondary caries at various anatomical locations. Oper Dent, 1985; 10:88-92.

70. Hahnel S, Henrich A, Rosentritt M, Handel G, Bürgers R. Influence of artificial ageing on surface properties and Streptococcus mutans adhesion to dental composite materials. J Mater Sci Mater Med, 2010; 21:823-833.

71. Ionescu A, Brambilla E, Wastl DS, Giessibl FJ, Cazzaniga G, Schneider-Feyrer S, Hahnel S. Influence of matrix and filler fraction on biofilm formation on the surface of experimental resin-based composites. J Mater Sci Mater Med, 2015; 26:5372.

72. Kidd EA, Joyston-Bechal S, Beighton D. Microbiological validation of assessments of caries activity during cavity preparation. Caries Res, 1993; 27:402-408.

73. Splieth C, Bernhardt O, Heinrich A, Bernhardt H, Meyer G. Anaerobic microflora under Class I and Class II composite and amalgam restorations. Quintessence Int, 2003; 34:497-503.

74. Mo SS, Bao W, Lai GY, Wang J, Li MY. The microfloral analysis of secondary caries biofilm around Class I and Class II composite and amalgam fillings. BMC Infect Dis, 2010; 10:241.

75. Özer L, Thylstrup A. What is known about caries in relation to restorations as a reason for replacement? A review. Adv Dent Res, 1995; 9:394-402.

76. Gilmour AS, Edmunds DH, Dummer PM. The production of secondary caries-like lesions on cavity walls and the assessment of microleakage using an in vitro microbial caries system. J Oral Rehabil, 1990; 17:573-578.

77. Diercke K, Lussi A, Kersten T, Seemann R. Isolated development of inner (wall) caries like lesions in a bacterial-based in vitro model. Clin Oral Investig, 2009; 13:439444.

78. Nassar HM, Gonzalez-Cabezas C. Effect of gap geometry on secondary caries wall lesion development. Caries Res, 2011; 45:346-352. 
79. Wopenka B, Pasteris JD. A mineralogical perspective on the apatite in bone. Mater Sci Eng C Mater Biol Appl, 2005; 25:131-143.

80. Carlström D. Polarization microscopy of dental enamel with reference to incipient carious lesions. Adv Oral Biol, 1964:1:255-296.

81. Hals E, Halse A. Electron probe microanalysis of secondary carious lesions associated with silver amalgam fillings. Acta Odontol Scand, 1975; 33:149-160.

82. Silva M, Zimmerman BF, Weinberg R, Sarkar NK. Corrosion and artificial caries-like lesions around amalgam restorations. Aust Dent J, 1987; 32:116-119.

83. Marek M, Hochman RF. A simulated crevice corrosion experiment for $\mathrm{pH}$ and solution chemistry determination. Corrosion, 1974; 30:208-210.

84. Sutow EJ, Jones DW, Hall GC, Owen CG. Crevice corrosion products of dental amalgam. J Dent Res, 1991; 70:1082-1087.

85. Mahler DB, Pham BV, Adey JD. Corrosion sealing of amalgam restorations in vitro. Oper Dent, 2009; 34:312-320.

86. Scholtanus JD, Ozcan M, Huysmans MCDNJM. Penetration of amalgam constituents into dentine. J Dent, 2009; 37:366-373.

87. Grieve AR, Jones JC. An in vitro study of marginal leakage associated with composite restorations using an acidified agar technique. J Oral Rehabil, 1980; 7:215223.

88. Chen Y, Otis L, Piao D, Zhu Q. Characterization of dentin, enamel, and carious lesions by a polarization-sensitive optical coherence tomography system. Appl Opt, 2005; 44:2041-2048.

89. Vidal BC. Form birefringence as applied to biopolymer and inorganic material supraorganization. Biotech Histochem, 2010; 85:365-378.

90. Hedegård B. Need for correlation between laboratory testing and clinical research. In: National Bureau of Standards Special Publication 354. Dent Mater, research proceedings of the 50th anniversary symposium, October 6-8, 1968. U.S. Department of Commerce, 1972:187-189.

91. Ferracane JL. Resin-based composite performance: are there some things we can't predict? Dent Mater, 2013; 29:51-58.

92. Mjör IA. Glass-ionomer cement restorations and secondary caries: a preliminary report. Quintessence Int, 1996; 27:171-174. 
93. Randall RC, Wilson NHF. Glass-ionomer restoratives: a systematic review of a secondary caries treatment effect. J Dent Res, 1999; 78:628-637.

94. Papagiannoulis L, Kakaboura A, Eliades G. In vivo vs in vitro anticariogenic behavior of glass-ionomer and resin composite restorative materials. Dent Mater, 2002; 18:561-569.

95. Erickson RL, Glasspoole EA. Model investigations of caries inhibition by fluoridereleasing dent materials. Adv Dent Res, 1995; 9:315-323.

96. Wiegand A, Buchalla W, Attin T. Review on fluoride-releasing restorative materials-fluoride release and uptake characteristics, antibacterial activity and influence on caries formation. Dent Mater, 2007; 23:343-362.

97. Cenci MS, Tenuta LMA, Pereira-Cenci T, Del Bel Cury AA, ten Cate JM, Cury JA. Effect of Microleakage and Fluoride on Enamel-Dentine Demineralization around Restorations. Caries Res, 2008; 42:369-379.

98. Cenci MS, Pereira-Cenci T, Cury JA, Ten Cate JM. Relationship between gap size and dentine secondary caries formation assessed in a microcosm biofilm model. Caries Res, 2009; 43:97-102.

99. Nelsen RJ, Wolcott RB, Paffenbarger GC. Fluid exchange at the margins of dental restorations. J Am Dent Assoc, 1952; 44:288-295.

100. Sausen RE, Armstrong WD, Simon WJ. Penetration of radiocalcium at margins of acrylic restorations made by compression and noncompression technics. J Am Dent Assoc, 1953; 47:636-639.

101. Swartz ML, Phillips RW. In vitro studies on the marginal leakage of restorative materials. J Am Dent Assoc, 1961; 62:141-151.

102. Going RE, Sawinski VJ. Microleakage of a new restorative material. J Am Dent Assoc, 1966; 73:107-115.

103. Sano H, Takatsu T, Ciucchi B, Horner JA, Matthews WG, Pashley DH. Nanoleakage: leakage within the hybrid layer. Oper Dent, 1995; 20:18-25.

104. Wu W, Cobb E, Dermann K, Rupp NW. Detecting margin leakage of dental composite restorations. J Biomed Mater Res, 1983; 17:37-43.

105. Roydhouse RH. Penetration around the margins of restorations. 2. Nature and significance. J Can Dent Assoc, 1968; 34:21-28. 
106. Loiselle FJ, Goldberg AF, Gross RL, Stuever CH Jr. Marginal microleakage—an in vivo assessment. J Am Dent Assoc, 1969; 78:758-760.

107. Going RE. Microleakage around dental restorations: a summarizing review. J Am Dent Assoc, 1972; 84:1349-1357.

108. Jodaikin A. Experimental microleakage around ageing dental amalgam restorations: a review. J Oral Rehabil, 1981; 8:517-526.

109. Shortall AC. Microleakage, marginal adaptation and composite resin restorations. Br Dent J, 1982; 153:223-237.

110. Taylor MJ, Lynch E. Microleakage. J Dent, 1992; 20:3-10.

111. Söderholm KJ. Correlation of in vivo and in vitro performance of adhesive restorative materials: a report of the ASC MD156 Task Group on Test Methods for the Adhesion of Restorative Materials. Dent Mater, 1991; 7:74-83.

112. Raskin A, D'Hoore W, Gonthier S, Degrange M, Déjou J. Reliability of in vitro microleakage tests: A literature review. J Adhes Dent, 2001; 3:295-308.

113. Raskin A, Tassery H, D'Hoore W, Gonthier S, Vreven J, Degrange M, Déjou J. Influence of the number of sections on reliability of in vitro microleakage evaluations. Am J Dent, 2003; 16:207-210.

114. Sarrett DC. Prediction of clinical outcomes of a restoration based on in vivo marginal quality evaluation. J Adhes Dent, 2007; 9 Suppl 1:117-120.

115. Schmid-Schwap M, Graf A, Preinerstorfer A, Watts DC, Piehslinger E, Schedle A. Microleakage after thermocycling of cemented crowns-a meta-analysis. Dent Mater, 2011; 27:855-869.

116. Hilton TJ. Can modern restorative procedures and materials reliably seal cavities? In vitro investigations. Part 1. Am J Dent, 2002; 15:198-210.

117. Hilton TJ. Can modern restorative procedures and materials reliably seal cavities? In vitro investigations. Part 2. Am J Dent, 2002; 15:279-289.

118. Mente J, Ferk S, Dreyhaupt J, Deckert A, Legner M, Staehle HJ. Assessment of different dyes used in leakage studies. Clin Oral Investig, 2010; 14:331-338.

119. Gale MS, Darvell BW. Dentine permeability and tracer tests. J Dent, 1999; 27:1-11.

120. Morresi AL, D'Amario M, Capogreco M, Gatto R, Marzo G, D'Arcangelo C, Monaco A. Thermal cycling for restorative materials: does a standardized protocol exist in laboratory testing? A literature review. J Mech Behav Biomed Mater, 2014; 29:295-308. 
121. Deng D, Yang H, Guo J, Chen X, Zhang W, Huang C. Effects of different artificial ageing methods on the degradation of adhesive-dentine interfaces. J Dent, 2014; 42:1577-1585.

122. Khvostenko D, Salehi S, Naleway SE, Hilton TJ, Ferracane JL, Mitchell JC, Kruzic JJ. Cyclic mechanical loading promotes bacterial penetration along composite restoration marginal gaps. Dent Mater, 2015; 31:702-710.

123. Jacquot B, Durand JC, Farge P, Valcarcel J, Deville de Périère D, Cuisinier F. Influence of temperature and relative humidity on dentin and enamel bonding: a critical review of the literature. Part 1. Laboratory studies. J Adhes Dent, 2012; 14:433-446.

124. D'Alpino PH, Pereira JC, Svizero NR, Rueggeberg FA, Pashley DH. Use of fluorescent compounds in assessing bonded resin-based restorations: a literature review. J Dent, 2006; 34:623-634.

125. Watson TF. A confocal optical microscope study of the morphology of the tooth/restoration interface using Scotchbond 2 dentin adhesive. J Dent Res, 1989; 68:1124-1131.

126. Duschner H, Ernst CP, Götz H, Rauscher M. Advanced techniques of microanalysis and confocal microscopy: perspectives for studying chemical and structural changes at the interface between restorative materials and the cavity wall. Adv Dent Res 1995; 9:355-362.

127. Sun J, Eidelman N, Lin-Gibson S. 3D mapping of polymerization shrinkage using X-ray micro-computed tomography to predict microleakage. Dent Mater, 2009; 25:314320.

128. Bakhsh TA, Sadr A, Shimada Y, Tagami J, Sumi Y. Non-invasive quantification of resin-dentin interfacial gaps using optical coherence tomography: validation against confocal microscopy. Dent Mater, 2011; 27:915-925.

129. Makishi P, Shimada Y, Sadr A, Tagami J, Sumi Y. Non-destructive 3D imaging of composite restorations using optical coherence tomography: marginal adaptation of self-etch adhesives. J Dent, 2011; 39:316-325.

130. Turkistani A, Sadr A, Shimada Y, Nikaido T, Sumi Y, Tagami J. Sealing performance of resin cements before and after thermal cycling: evaluation by optical coherence tomography. Dent Mater, 2014; 30:993-1004.

131. Lucena C, Lopez JM, Abalos C, Robles V, Pulgar R. Statistical errors in microleakage studies in operative dentistry. A survey of the literature 2001-2009. Eur J Oral Sci, 2011; 119:504-510. 
132. Lucena C, Lopez JM, Pulgar R, Abalos C, Valderrama MJ. Potential errors and misuse of statistics in studies on leakage in endodontics. Int Endod J, 2013; 46:323331.

133. Alptekin T, Ozer F, Unlu N, Cobanoglu N, Blatz MB. In vivo and in vitro evaluations of microleakage around Class I amalgam and composite restorations. Oper Dent, 2010; 35:641-648.

134. Abdalla Al, Davidson CL. Comparison of the marginal integrity of in vivo and in vitro Class II composite restorations. J Dent, 1993; 21:158-162.

135. Opdam NJ, Feilzer AJ, Roeters JJ, Smale I. Class I occlusal composite resin restorations: in vivo post-operative sensitivity, wall adaptation, and microleakage. Am J Dent, 1998; 11:229-234.

136. Fuks AB, Chosack A, Eidelman E. Two-year evaluation in vivo and in vitro of Class 2 composites. Oper Dent, 1990; 15:219-223.

137. Holan G, Chosack A, Casamassimo PS, Eidelman E. Marginal leakage of impregnated Class 2 composites in primary molars: an in vivo study. Oper Dent, 1992; 17:122-128.

138. Ellis JM, Brown LR. Application of an in vitro cariogenic technic to study the development of carious lesions around dental restorations. J Dent Res, 1967; 46:403408.

139. Derand T, Birkhed D, Edwardsson S. Secondary caries related to various marginal gaps around amalgam restorations in vitro. Swed Dent J, 1991; 15:133-138.

140. Totiam P, Gonzalez-Cabezas C, Fontana MR, Zero DT. A new in vitro model to study the relationship of gap size and secondary caries. Caries Res, 2007; 41:467-473.

141. Kuper NK, Opdam NJ, Bronkhorst EM, Ruben JL, Huysmans MCDNJM. Hydrodynamic flow through loading and in vitro secondary caries development. J Dent Res, 2013; 92:383-387.

142. Thomas RZ, Ruben JL, ten Bosch JJ, Fidler V, Huysmans MCDNJM. Approximal secondary caries lesion progression, a 20-week in situ study. Caries Res, 2007; 41:399405.

143. van de Sande FH, Opdam NJ, Truin GJ, Bronkhorst EM, de Soet JJ, Cenci MS, Huysmans MCDNJM. The influence of different restorative materials on secondary caries development in situ. J Dent, 2014; 42:1171-1177. 
144. Kuper NK, Opdam NJ, Ruben JL, de Soet JJ, Cenci MS, Bronkhorst EM, Huysmans MCDNJM. Gap size and wall lesion development next to composite. J Dent Res, 2014; 93(7 Suppl):108S-113S.

145. Lobo MM, Gonçalves RB, Ambrosano GMB, Pimenta LAF. Chemical or microbiological models of secondary caries development around different dental restorative materials. J Biomed Mater Res B Appl Biomater, 2005; 74:725-731.

146. Toledano M, Aguilera FS, Osorio E, Cabello I, Toledano-Osorio M, Osorio R. Mechanical and chemical characterisation of demineralised human dentine after amalgam restorations. J Mech Behav Biomed Mater, 2015; 47:65-76.

147. Downer MC, Azli NA, Bedi R, Moles DR, Setchell DJ. How long do routine dental restorations last? A systematic review. Br Dent J, 1999; 187:432-439.

148. Chadwick B, Treasure E, Dummer P, Dunstan F, Gilmour A, Jones R, Phillips C, Stevens J, Rees J, Richmond S. Challenges with studies investigating longevity of dental restorations--a critique of a systematic review. J Dent, 2001; 29:155-161.

149. Astvaldsdottir A, Dagerhamn J, van Dijken JW, Naimi-Akbar A, SandborghEnglund G, Tranæus S, Nilsson M. Longevity of posterior resin composite restorations in adults - A systematic review. J Dent, 2015; 43:934-954.

150. Jokstad A, Mjör IA. Cavity designs for class II amalgam restorations. A literature review and a suggested system for evaluation. Acta Odontol Scand, 1987; 45:257-273.

151. Jokstad A, Mjör I. A. The quality of routine Class II cavity preparations for amalgam. Acta Odontol Scand, 1989; 47:53-64.

152. Jokstad A. The dimensions of the everyday Class II cavity preparations for amalgam. Acta Odontol Scand, 1989; 47:89-99.

153. Jokstad A, Johannessen L, Qvist V, Mjör IA. Class I and II cavities for amalgam restorations. Tandlaegebladet, 1989; 93:230-236.

154. Mjör IA, Jokstad A. Five-year study of Class II restorations in permanent teeth using amalgam, glass polyalkenoate (ionomer) cermet and resin-based composite materials. J Dent, 1993; 21:338-343.

155. Jokstad A, Mjör IA. Analyses of long term clinical behavior of class II amalgam restorations. Acta Odontol Scand, 1991; 49:47-63.

156. Jokstad A, Mjör IA. Replacement reasons and service time of class II amalgam restorations in relation to cavity design. Acta Odontol Scand, 1991; 49:109-126. 
157. Rekow ED, Fox CH, Watson $\mathrm{T}$, Petersen PE. Future innovation and research in dental restorative materials. Adv Dent Res, 2013; 25:2-7. 
Table 1. Conclusions made by authors of reviews of microleakage studies over the last four decades

\begin{tabular}{|c|c|}
\hline Author & Main conclusion \\
\hline 1968, Roydhouse [105] & $\begin{array}{l}\text {... of limited value ... because many variables are not accounted for. Tests } \\
\text { may demonstrate a potential, but not a clinical reality }\end{array}$ \\
\hline 1969, Loiselle et al. [106] & ...these tests eliminate the effect of pulpal hydrostatic pressure and plaque \\
\hline 1972, Going [107] & ...most methods fall scientifically short in providing quantitative data \\
\hline 1981, Jodaikin [108] & $\begin{array}{l}\text {...no direct comparison possible between in vitro \& in vivo due to many } \\
\text { variables }\end{array}$ \\
\hline 1982, Shortall [109] & $\begin{array}{l}\ldots \text { the results can be partly or totally influenced by the variations of the } \\
\text { methodology applied }\end{array}$ \\
\hline 1992, Taylor \& Lynch [110] & ...wide variations in methodologies are revealed \\
\hline 1991, Söderholm [111] & ...the relevance in a testing protocol for dentin adhesion must be questioned \\
\hline 2001, Raskin et al. [112] & ...results from different testing institutes could not be compared \\
\hline 2003, Raskin et al. [113] & ...results from different testing institutes are hardly reproducible \\
\hline 2007, Sarrett [114] & $\begin{array}{l}\text {..evidence for a direct relationship between poor marginal quality as } \\
\text { promoter or primary cause for secondary caries is limited, and any direct } \\
\text { relationship is unlikely }\end{array}$ \\
\hline 2007, Heintze [4] & ...it does not make sense to use this elaborate labor-intensive method \\
\hline $\begin{array}{l}\text { 2011, Schmid-Schwap et al. } \\
\text { [115] }\end{array}$ & ...not possible to make a quantitative synthesis due to study heterogeneity \\
\hline 2011 Heintze \& Zimmerli [5] & $\begin{array}{l}\text {...dye penetration... do not correlate or correlate only partially with clinical } \\
\text { findings }\end{array}$ \\
\hline 2012, Bayne [6] & $\begin{array}{l}\text {... no correlation of microleakage with any clinical event has ever been } \\
\text { established }\end{array}$ \\
\hline 2012, Dennison \& Sarrett [7] & $\begin{array}{l}\text {...clinical evidence refute earlier conclusions that clinical microleakage leads } \\
\text { to secondary caries }\end{array}$ \\
\hline 2013, Heintze [8] & $\begin{array}{l}\text {...moderate evidence that dye penetration tests does not correlate with } \\
\text { clinical data }\end{array}$ \\
\hline 2013, Dietschi et al. & ure should be strictly limited \\
\hline
\end{tabular}


Table 2. Conclusions made from experimental microleakage studies versus clinical observations.

\begin{tabular}{|l|l|l|}
\hline Clinical variable & Suggestion & Clinical observations \\
\hline Incremental vs bulk filling & Less microleakage & Corroborate \\
\hline Different curing approaches & conflicting results & $?$ \\
\hline Enamel vs dentin margins & Less microleakage & Corroborate \\
\hline Light cured vs self-cured & Less microleakage & Corroborate \\
\hline & & \\
\hline Matrix system & conflicting results & $?$ \\
\hline Primer solvent & Effect on dentin, not enamel & Corroborate \\
\hline Incorrect cavity drying & More microleakage & Corroborate \\
\hline Boxed cavity form & More microleakage than if rounded & Corroborate \\
\hline Sharp margins & More microleakage than if beveled & $?$ \\
\hline Occlusal loading & More microleakage than if no loading & $?$ \\
\hline & & \\
\hline Thick flowable liner & Less microleakage in enamel (- dentin & $?$ \\
\hline Adhesive brand & conflicting results & $?$ \\
\hline Flowable u. packable resin & conflicting results & $?$ \\
\hline rmGIC u. composite & conflicting results & $?$ \\
\hline Flowable u. rmGIC & conflicting results & $?$ \\
\hline Composite vs packable resin & Less microleakage in dentin & $?$ \\
\hline & & $?$ \\
\hline Etch-and-rinse vs self-etch & conflicting results & Corroborate \\
\hline Single versus two layers & Less microleakage & Corroborate \\
\hline Composite brand & conflicting results & $?$ \\
\hline Composite vs ormocer & conflicting results & \\
\hline Composite direct vs indirect & conflicting results & $?$ \\
\hline & & $?$ \\
\hline
\end{tabular}


Figure 1. Illustration of the range of different tooth-restoration interface for the range of restorative materials used today for intra- and extracoronal restorations. Boxed areas indicate examples of restorations deficiencies.

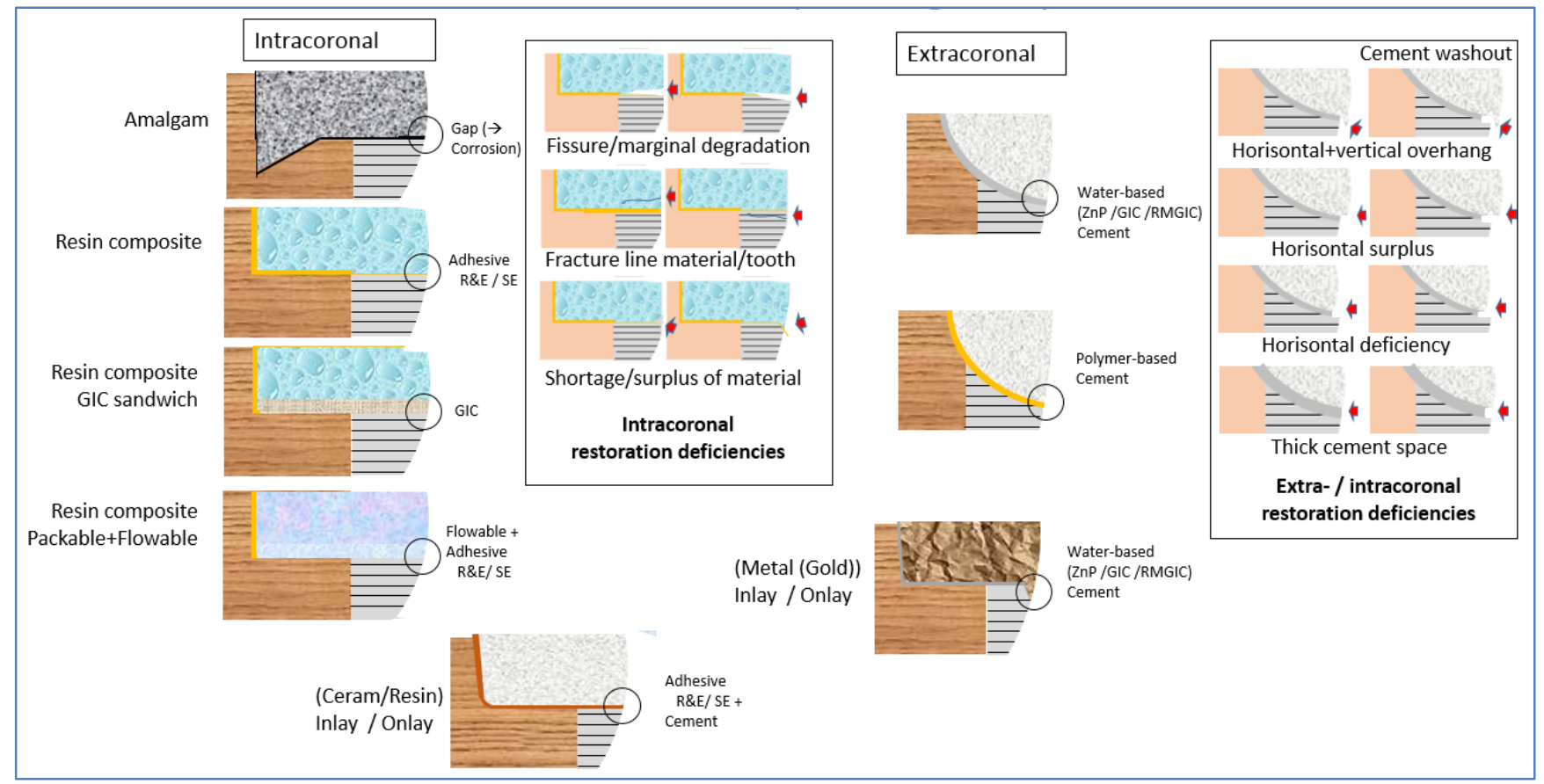


Figure 2. Variations of research experiments to clarify etiopathogenesis or prevention of secondary caries.

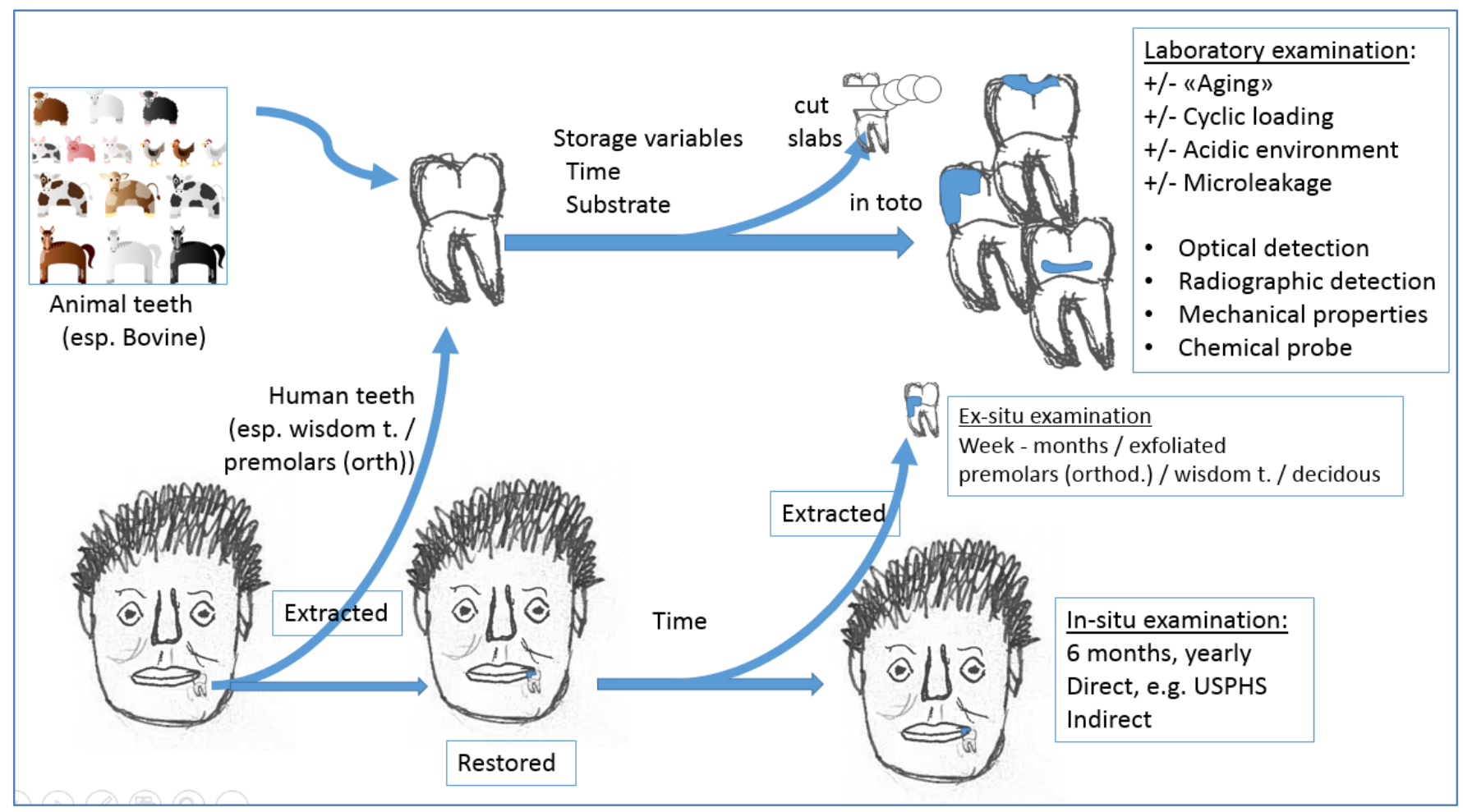

